\title{
Will Danford's Lizard Become Extinct in the Future?
}

\author{
Akın Kıraç ${ }^{1 *}$, Ahmet Mert ${ }^{2}$ \\ ${ }^{1}$ Vocational School of Technical Sciences, Çanakkale Onsekiz Mart University, Çanakkale, Turkey \\ ${ }^{2}$ Department of Wildlife Ecology and Management, Faculty of Forestry, Isparta University of Applied Sciences, \\ Isparta, Turkey
}

Received: 15 January 2018

Accepted: 11 April 2018

\begin{abstract}
Climate change created predominantly by burning fossil fuels leads to increased pressure on biodiversity. It may cause extinction in lizard species over the forthcoming years. Lizard species that are unable to adjust rapidly enough to the ecological alterations due to climate change are particularly under threat. Therefore, vulnerable lizard species should be monitored and adopt climate change scenarios. This study examines the changes in the habitats of Danford's lizard (Anatololacerta danfordi) according to the RCP 4.5 and RCP 8.5 (HADGEM2-ES) climate scenarios. We modelled the current habitat preferences of $A$. danfordi using the MaxEnt method based on the bioclimatic features derived from Worldclim. Our results showed that A.danfordi prefers habitats with the bioclimate features including $12 \mathrm{~mm}$ for precipitation of driest month, $1-2^{\circ} \mathrm{C}$ for mean temperature of wettest quarter, $-4^{\circ} \mathrm{C}$ for min temperature of coldest month, and $600 \mathrm{~mm}$ for annual precipitation. We determined the potential distributions of the A.danfordi using the model and GIS facilities for both RCP 4.5 and RCP 8.5 climate scenarios. In conclusion, the potential habitats of this lizard species may be dramatically influenced from two climate scenarios. We envisage that the suitable habitats may be mostly relocated from the south toward the north. A.danfordi may not adapt this rapid change and may not migrate to new suitable locations within this short period. Therefore, governments should make provisions against climate change without delay.
\end{abstract}

Keywords: climate change, lizard, MaxEnt, RCP 4.5, RCP 8.5

\section{Introduction}

Global climate change is undoubtedly a threat to ecosystems and biodiversity [1]. Looking at the IPCC [2], the increase in mean global air temperature associated with the increasing concentrations of

*e-mail: akinkirac84@gmail.com atmospheric $\mathrm{CO}_{2}$ has been by 0.72 to $1.06^{\circ} \mathrm{C}$ since its preindustrial period. That is projected to be by 1.67 to $2.78^{\circ} \mathrm{C}$ (at $\sim 550 \mathrm{ppmv}$ ) and by 2.78 to $5.56^{\circ} \mathrm{C}$ (at $\sim 625$ and $850 \mathrm{ppmv}$ ) for lower and higher emission scenarios, respectively. After the IPCC Fourth Assessment Report [3] was published, the Turkish General Directorate of Meteorology [4] prepared a climate change report for Turkey. According to the temperature and rainfall projections produced using HadGEM2-ES based on 
the RCP 4.5 scenario, in Turkey it is predicted that in 2050 the temperature will generally be limited to $3-4^{\circ} \mathrm{C}$ and the precipitation will decrease by $20 \%$. In 2070 the temperature will exceed $4^{\circ} \mathrm{C}$ and rains will decrease by $40 \%$ in summer. According to the temperature and precipitation projections using HadGEM2-ES based on the RCP 8.5 scenario; it is predicted that there will be an increase of $5^{\circ} \mathrm{C}$ in Turkey in 2050 and that rainfall will decrease by $50 \%$. In 2070 , especially summer temperatures are expected to exceed $6^{\circ} \mathrm{C}$ and rainfall is expected to decrease by $50 \%$.

The change in temperature and rainfall will most likely result in habitat restriction for species with special climatic requirements [5]. The habitat restriction that will occur with global climate change is the cause of stress for wildlife [6]. In addition, organisms can adapt to global climate change, shift to potentially suitable habitats, or face the danger of extinction by failing to adapt to climate change [7].

Ectotherms are susceptible to climate change because environmental temperatures carry out a strong effect on multiple physiological duration such as daily mobility, feeding, digestion, metabolic energy, body size, growth, and reproduction [8-9]. Lizards are ectothermic organisms; therefore they often have limited climatic tolerance and are strongly dependent on climatic conditions [10]. Reduction in and extinction of reptile populations has occurred in some parts of the world and climate change is one of the reasons for explaining this decline [11]. Recent studies suggest that lizards will be affected by climate change and that the risk of extinction of lizards toward the end of the century is likely [7, 12-14]. According to Sinervo et al. [13], climate change will cause the extinction of $40 \%$ of all global lizard populations and $56 \%$ of European Lacertidae by 2080. However, these results were obtained with traditional biological models.

MaxEnt (maximum entropy) has been proven to be more successful than other traditional biological models that estimate ecological requirements and predict potential distribution [15-17]. The ability to predict the potential distribution of lizard species under climate change is crucial in order to achieve a greater understanding of the future evolution of ecosystems -

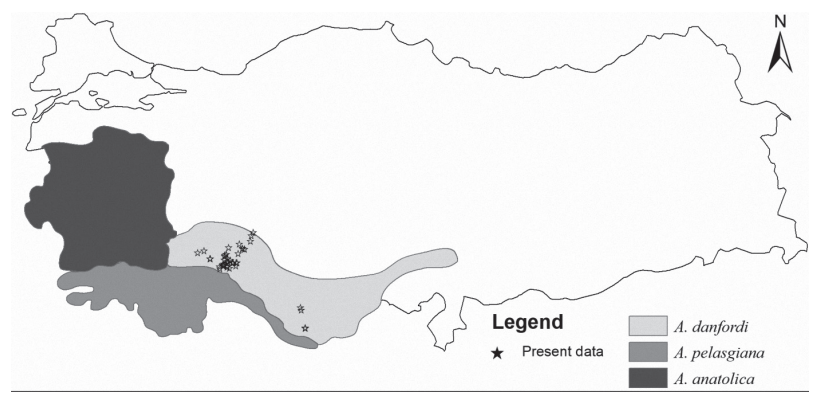

Fig. 2. Distribution of A.danfordi [19, 21].

in particular Mediterranean ecosystems. Accordingly, habitat suitability maps can be extremely useful in predicting the distribution of critical species and monitoring future habitat differences [5].

Anatololacerta danfordi (Günter, 1876) (Reptilia:Lacertidae), distributed around West Taurus and Central Taurus in southern Turkey, is endemic to this region $[18,19]$. In this study, we determined the climatic factors affecting the distribution of Anatololacerta danfordi for the present. Later, for 2050 and 2070, we obtained a model based on RCP 4.5 and RCP 8.5 scenarios and determined the potential distribution of $A$. danfordi for the future. We performed all these modeling processes using the MaxEnt method. The application of MaxEnt for analysis is a preferred method in species distribution models because it gives more accurate results with less sample data than other methods [15].

\section{Material and Methods}

\section{Species Data and Bioclimate Data}

Between 2014 and 2017 we recorded 53 presence data for $A$. danfordi (Fig. 1) from around western and central Taurus (Burdur-Isparta-Beyşehir-KaramanMersin) (Fig. 2). Our presence records from A. danfordi include only adult individuals. Because the habitats in which juvenile individuals are located may be habitats that have been forced to live due to hunter pressure and

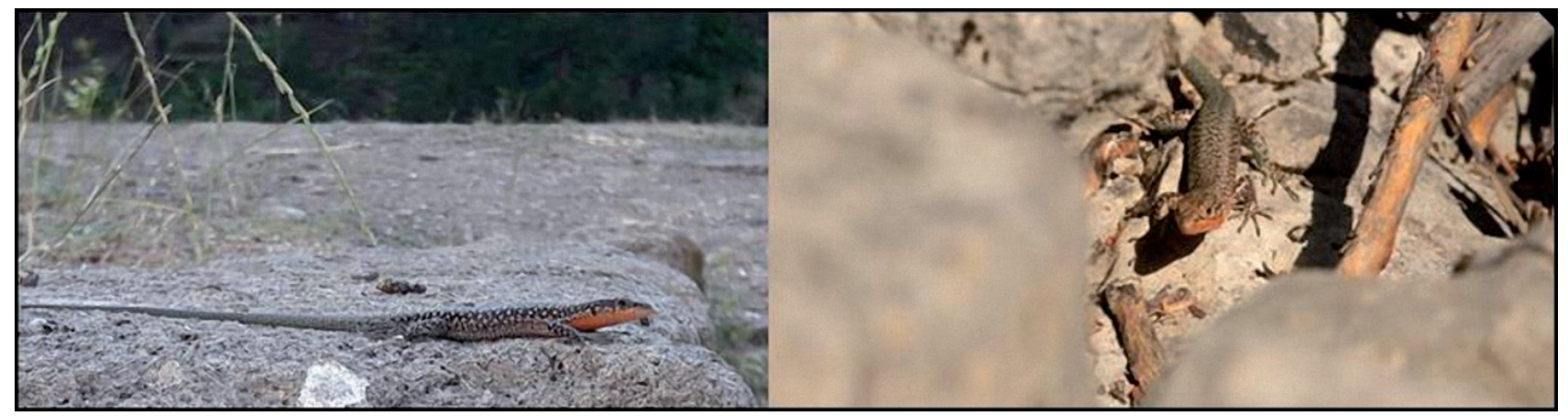

Fig. 1. Anatololacerta danfordi. 
Table 1. Bioclimatic variables.

\begin{tabular}{|c|c|c|c|}
\hline Code & Bioclimatic Variables & Unit & Contribution $\%$ \\
\hline Bio1 & Annual Mean Temperature & ${ }^{\circ} \mathrm{C}$ & \\
\hline Bio2 & Mean Diurnal Range (Mean of monthly (max temp - min temp)) & ${ }^{\circ} \mathrm{C}$ & \\
\hline Bio3 & Isothermality $\left.(\mathrm{BIO} 2 / \mathrm{BIO} 7)^{*} 100\right)$ & - & \\
\hline Bio4 & Temperature Seasonality (standard deviation *100) & $\mathrm{C}$ of $\mathrm{V}$ & \\
\hline Bio5 & Max Temperature of Warmest Month & ${ }^{\circ} \mathrm{C}$ & 0.00 \\
\hline Bio6 & Min Temperature of Coldest Month & ${ }^{\circ} \mathrm{C}$ & 14.4 \\
\hline Bio7 & Temperature Annual Range (BIO5-BIO6) & ${ }^{\circ} \mathrm{C}$ & \\
\hline Bio8 & Mean Temperature of Wettest Quarter & ${ }^{\circ} \mathrm{C}$ & 36.2 \\
\hline Bio9 & Mean Temperature of Driest Quarter & ${ }^{\circ} \mathrm{C}$ & \\
\hline Bio10 & Mean Temperature of Warmest Quarter & ${ }^{\circ} \mathrm{C}$ & \\
\hline Bio11 & Mean Temperature of Coldest Quarter & ${ }^{\circ} \mathrm{C}$ & $\mathbf{0 . 0 0}$ \\
\hline Bio12 & Annual Precipitation & mm & 12.2 \\
\hline Bio13 & Precipitation of Wettest Month & $\mathrm{mm}$ & \\
\hline Bio14 & Precipitation of Driest Month & mm & 37.1 \\
\hline Bio15 & Precipitation Seasonality (Coefficient of Variation) & $\mathrm{C}$ of $\mathrm{V}$ & \\
\hline Bio16 & Precipitation of Wettest Quarter & $\mathrm{mm}$ & \\
\hline Bio17 & Precipitation of Driest Quarter & $\mathrm{mm}$ & \\
\hline Bio18 & Precipitation of Warmest Quarter & $\mathrm{mm}$ & \\
\hline Bio19 & Precipitation of Coldest Quarter & $\mathrm{mm}$ & \\
\hline
\end{tabular}

Note: The highlighted variables, selected through Pearson Correlation Analysis, were used in modeling.

competition, and there may be lower-quality habitats for adults [20].

In addition to presence data, MaxEnt models also require importing ascii layers that describe the environmental conditions of specific interest for measuring against the study species. The WorldClim dataset uses altitude, temperature, and precipitation to reproduce monthly, quarterly, and annual climate indices to represent trends, seasonality, and extremes that are biologically relevant [22]. In this case, the WorldClim's 19 bioclimatic variables (v.1.4) (Table 1) were used for 1950-2000, 2050 (HadGEM2-ES RCP 4.5 and 8.5 scenario), and 2070 (HadGEM2-ES RCP 4.5 and 8.5 scenario) (www.worldclim.org). This dataset is presented as latitude/longitude coordinates in WGS84 with approximately $1 \mathrm{~km}^{2}$ cell size.

In order to remove the multiple connection problem among the bioclimatic data, we applied Pearson Correlation Analysis $\left(\mathrm{R}^{2}<0.85\right)$. As a result, Bio5 (max temperature of warmest month), Bio6 (min temperature of coldest month), Bio8 (mean temperature of wettest quarter), Bioll (mean temperature of coldest quarter), Bio12 (annual precipitation), and Biol4 (precipitation of driest month) were selected as bioclimatic variables to be used during the modeling phase.

\section{MaxEnt and Habitat Suitability Model}

MaxEnt 3.4.1 software was used to assess the potential distribution of A.danfordi. We selected MaxEnt as the most appropriate type of distribution modeling method for our study, due to it having a higher estimation power and delivering better and more accurate results with less presence data of target species. The A.danfordi presence data entered is in the "samples" file, and the location of the BioClim layers folder is entered under "environmental layers." Future projection data is entered under the projection layers directory/file. Each climate model and climate scenario for 2050 (RCP 4.5; 8.5) and 2070 (RCP 4.5; $8.5)$ are then tested independently. Ninety percent of the presence data was set as training data and 10\% as test data, with 10 repetitions [16]. We used area under the receiver operating characteristic (ROC) curves (AUC) for evaluating model performance [23]. The AUC value near 1 is identified as the perfect explanatory model. The AUC value of 0.7 is explained as descriptive, whereas the value of 0.5 is considered a non-informative model [24]. 


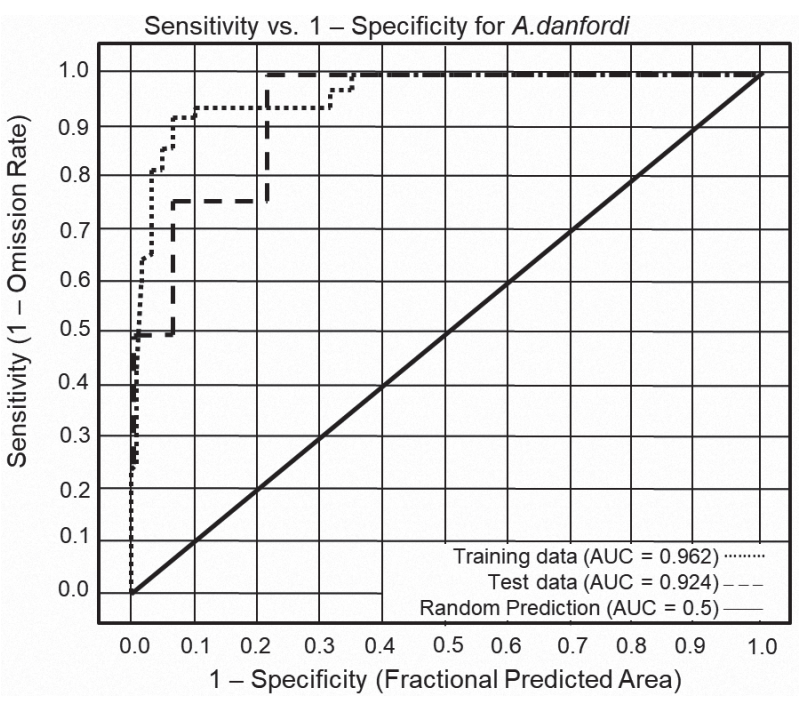

Fig. 3. Sensivity vs. 1- specificity graphic for Anatololacerta danfordi.

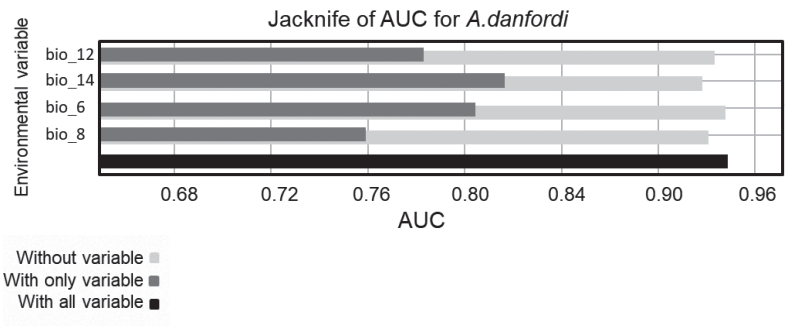

Fig. 4. Results of jacknife evaluations of relative importance of predictor variables for Anatololacerta danfordi.

\section{Results and Discussion}

As a result of the analysis, the training data AUC value is 0.962 and the test data AUC value is 0.924 (Fig. 3). Bioclimatic factors affecting the distribution of A.danfordi in the conclusion model are Biol4 (precipitation of driest month), Bio8 (mean temperature of wettest quarter), Bio6 (min temperature of coldest month), and Bio12 (annual precipitation). Bio5 (max temperature of warmest month) and Bio 11 (mean temperature of coldest quarter) made no contribution to the species distribution models. Today, A.danfordi prefers habitats that have values of $12 \mathrm{~mm}$ for precipitation of driest month, $1-2^{\circ} \mathrm{C}$ for mean temperature of wettest quarter, $-4^{\circ} \mathrm{C}$ for min temperature of coldest month, and $600 \mathrm{~mm}$ for annual precipitation (Figs. 4-5).

When the bioclimatic habitat compliance maps obtained for A.danfordi are examined, it is observed that bioclimatically suitable habitats are present in the middle and west Taurus (Mediterranean region), and potential bioclimatic suitable habitats are located in the southern and northern Aegean for today (Fig. 6a).

According to the RCP 4.52050 (HADGEM2-ES) scenario, suitable habitats of A.danfordi are predicted to be lost in middle Taurus. On the other hand, it is predicted that suitable habitats in western Taurus will continue, potentially suitable habitats in the southern and northern Aegean regions will continue, and new potentially suitable habitats will emerge in the inner parts of the western Black Sea region (Fig. 6b). It is expected that for the RCP 4.52070 scenario similar potential situations may apply, but unlike
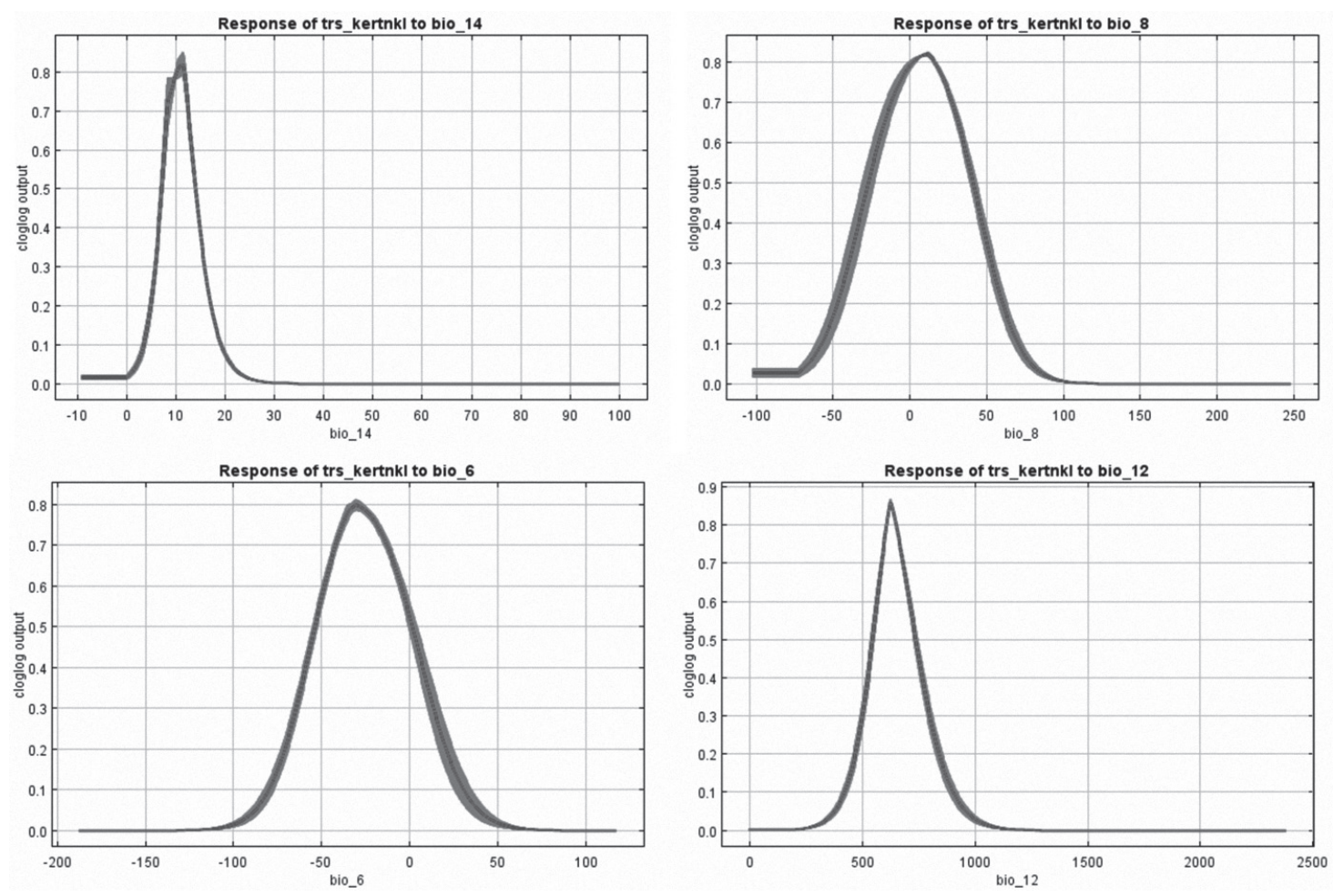

Fig. 5. Response curves of the four bioclimatic variables that limit the distribution of Anatololacerta danfordi. 
the RCP 4.52050 scenario, potentially suitable habitats in the inner parts of the western Black Sea region are expected to increase (Fig. 6c).

If the RCP 8.5 scenario, known as the worst scenario in the scenarios, occurs, it is envisaged that in 2050 the appropriate habitats will decrease according to the RCP 4.5 scenario (Fig. 6d). According to our conclusion for the RCP 8.52070 scenario, A. danfordi will lose nearly all suitable habitats in the western and central Taurus (Mediterranean region). On the other hand, it is envisaged that there will be few potential habitats in the south and north of the Aegean region, and new potential suitable habitats will emerge in the inner parts of the western Black Sea region (Fig. 6e).

a)

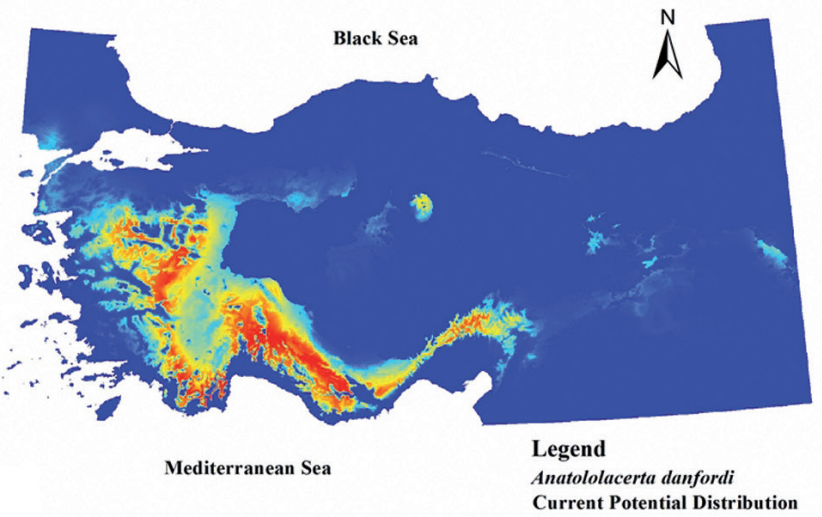

b)

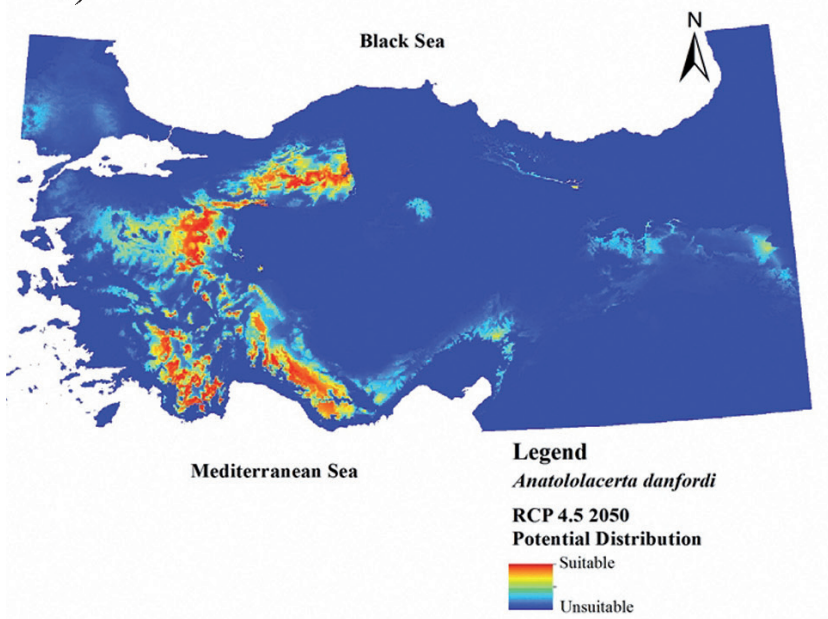

d)

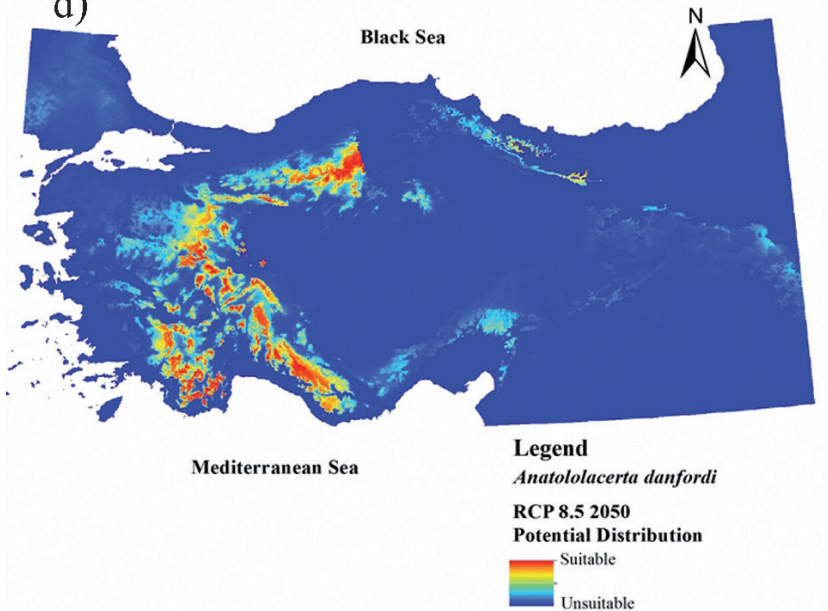

c)
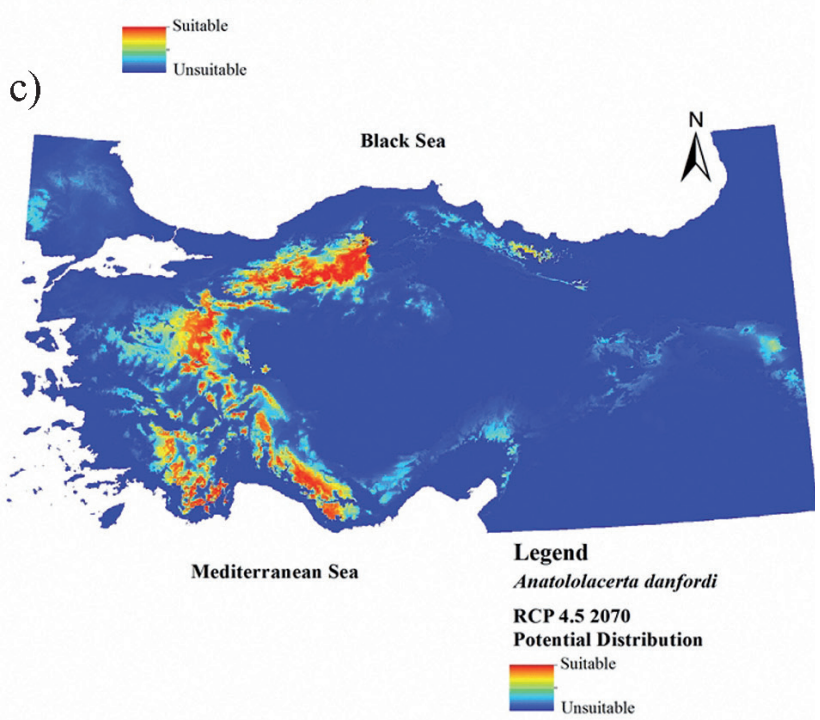

e)

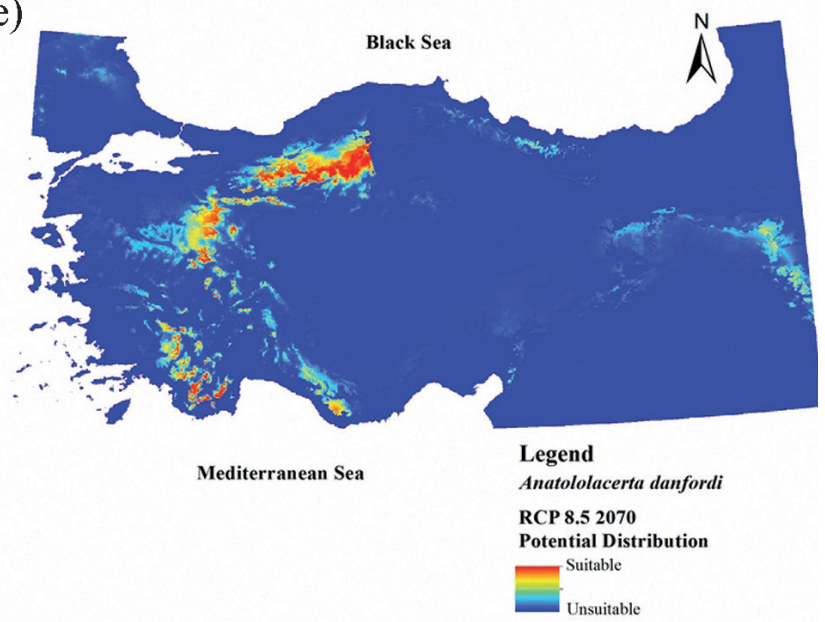

Fig. 6. Anatololacerta danfordi bioclimatic habitat suitability maps: a) Current, b) HADGEM2-ES RCP 4.5 2050, c) HADGEM2-ES RCP 4.5 2070, d) HADGEM2-ES RCP 8.5 2050, e) HADGEM2-ES RCP 8.5 2070. 


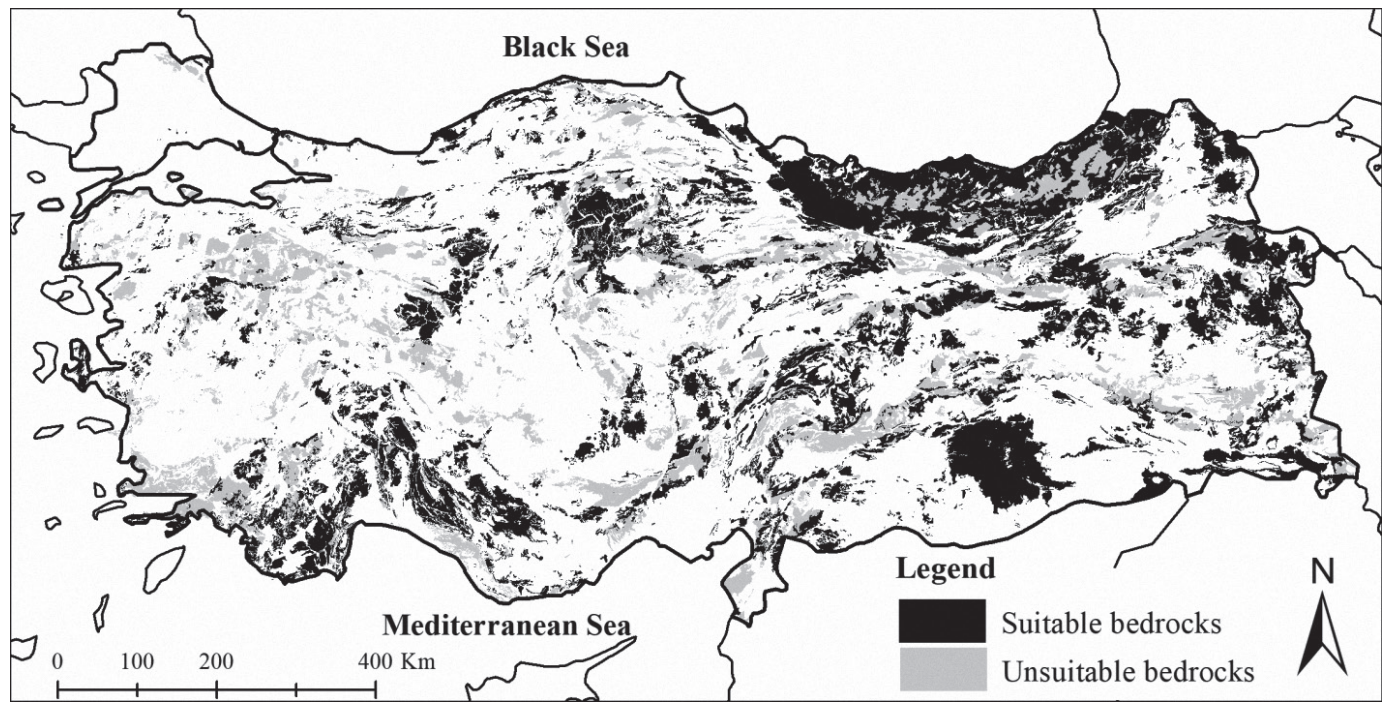

Fig. 7. Bedrock affecting the distribution of Anatololacerta danfordi.

\section{Conclusions}

According to Huey [25], environmental temperature is of great importance for lizard physiology, ecology, and behavior. However, based on our study results, we think that future changes in precipitation and humidity will affect lizard species such as $A$. danfordi with changes in environmental temperatures.

Climatic habitat suitability maps show habitats that will disappear with the impact of future climate change and climatically suitable habitats that will emerge in future, with reference to the climatic characteristics of habitats where the lizard is naturally distributed today. The main argument here is how A.danfordi populations will react to the disruption and disappearance of habitats and the emergence of new suitable habitats. These reactions can be discussed by producing two different scenarios based on migration and adaptation. But first, it is necessary to review the relationship between lizards like $A$. danfordi and ecological factors.

According to Mert and Kıraç [16], it is stated that the A.danfordi preference areas with bedrock types are travertine, volcano sedimentary rock, conglomerate and olistostrome (chert and peridotite do not prefer bedrock types), minimum slope, minimum ruggedness, U-shaped valleys, and humid areas. In addition, it was emphasized that the most effective environmental factor in the distribution of $A$. danfordi in the study was bedrock. Termoregulants such as A.danfordi use the rock surface and rock holes according to their shade and sun exposure features with the aim of regulating the proper range of body temperature. In the morning, direct sunlight (heliothermy) can be thermoregulated and shadows may be preferred to prevent overheating. When the sun's rays are no longer effective after the afternoon, thermoregulation can be achieved from the surface of the heated rocks (thigmothermy) [26]. In addition, bedrock in the cracked and perforated structure (travertine, volcano sedimentary rock, conglomerate, and olistostrome) can be used by $A$. danfordi as thermal shelters and to hide from predators in the event of danger.

Recent studies have talked about the migration mechanisms of species against climate change [7, 27]. In the scenario we produce based on migration, in the face of climate change, A. danfordi populations may shift from unsuitable habitats to potentially new suitable habitats. While A.danfordi shift to new suitable habitats, it will need corridors [7] that are most effective in its distribution, bedrocks, and U-shaped valleys [16]. Fig. 7 shows the preferred and non-preferred bedrocks by A.danfordi. Suitable bedrocks, shown in black on the map, show us that it may be more likely to pass into the new climatic suitable habitats in the west. However, migration to the north may not be possible with a barrier made up of unsuitable bedrocks, shown in grey on the map. If A.danfordi can pass this barrier, climatically suitable habitats emerging in the north have suitable bedrock groups. Another problem about migration is the result of competition between the two species (Anatololacerta pelasgiana and Anatololacerta anatolica) living in the west and north and A.danfordi $[18,19]$. Migration to new habitats can be a disadvantage in food competition against the species present in the environment. If nutritional stress results in failure to provide the necessary energy for reproduction and other vital activities, A.danfordi can complete this process with extinction. Although migration to new climatically suitable habitats seems to be a worthwhile way to try for A.danfordi, we think that 2050 and 2070 dates are short for particular migration to the north. However, when the temperature increase in existing habitats exceeds the appropriate temperature range for lizards, the lizards are expected to reduce the duration of their potential activity [28], and for this reason immigration is difficult. 
Our second scenario assumes $A$. danfordi will not migrate and will adapt to climate change. Adapting to the increase in temperature and the decrease in precipitation will bring about some changes in A.danfordi's daily activities. For example, the duration of activity for thermoregulation will change [29]. The time spent in shadow areas may increase to avoid overheating [28, 30]. Actually, this situation limits the time required for A.danfordi to search for food. Thus, A.danfordi, which cannot reach adequate amounts of food, will not be able to provide energy for important vital activities such as reproduction, and the process may result in the extinction of A.danfordi populations.

We discussed how scenarios based on migration and adaptation involve many problems [31]. We believe that the main solution is to reduce human activities such as fossil fuel consumption, which causes climate change [32-35], and that the future should be planned with ecological sensitivity. Measures to be taken against climate change may not be enough for 2050, but for 2070 it could be a better result.

\section{Acknowledgements}

We thank Prof. İbrahim ÖZDEMIR for his valuable contribution during our study.

\section{Conflict of Interest}

The authors declare no conflict of interest.

\section{References}

1. WALTHER G.R., POST E., CONVEY P., MENZEL A., PARMESAN C., BEEBEE T.J., BAIRLEIN F., Ecological responses to recent climate change. Nature, 416 (6879), 389, 2002.

2. IPCC (Intergovernmental Panel on Climate Change) [Online]. Climate Change: The Physical Science Basis. Summary for Policy Makers, [Accessed 22.09.2014.]. Available: http://www.ipcc.ch/, 2013.

3. IPCC (Intergovernmental Panel on Climate Change) [Online]. Climate Change: The Physical Science Basis. Summary for Policy Makers, [Accessed 21.09.2014.]. Available: http://www.ipcc.ch/, 2007.

4. AKÇAKAYA A., ESKİOĞLU O., ATAY H., DEMIR Ö. Yeni Senaryolarla Türkiye İçin İklim Değişikliği Projeksiyonları [New Climate Change Scenarios for Turkey], MGM, Ankara, 2013.

5. MERT A., ÖZKAN K., ŞENTÜRK Ö., NEGİZ M. G. Changing the Potential Distribution of Turkey Oak (Quercus cerris L.) under Climate Change in Turkey. Polish Journal of Environmental Studies, 25 (4), 2016.

6. PEREIRA H.M., LEADLEY P.W., PROENÇA V., ALKEMADE R., SCHARLEMANN SCHARLEMANN J.P., FERNANDEZ-MANJARRES J.F., CHINI L.
Scenarios for global biodiversity in the $21^{\text {st }}$ century. Science, 330.6010, 1496, 2010.

7. SINERVO B., LARA RESENDIZ R.A., MILES D.B., LOVICH J.E., ENNEN J.R., MÜLLER J., SITES Jr J.W. Climate Change and Collapsing Thermal Nivhes of Mexican Endemic Reptiles, 2017.

8. DEUTSCH C.A., TEWKSBURY J.J., HUEY R.B., SHELDON K.S., GHALAMBOR C.K., HAAK D.C., MARTIN, P. R. Impacts of climate warming on terrestrial ectotherms across latitude. Proceedings of the National Academy of Sciences, 105.18, 6668, 2008.

9. SHINE Richard. Life-history evolution in reptiles. Annu. Rev. Ecol. Evol. Syst., 36, 23, 2005.

10. BUCKLEY LAUREN B., KINGSOLVER JOEL G. Functional and phylogenetic approaches to forecasting species' responses to climate change. Annual Review of Ecology, Evolution, and Systematics, 43, 205, 2012.

11. ARAÚJO MIGUEL B., THUILLER WILFRIED, PEARSON RICHARD G. Climate warming and the decline of amphibians and reptiles in Europe. Journal of biogeography, 33.10, 1712, 2006.

12. KUBISCH E.L., CORBALAN V., IBARGÜENGOYTIA N.R., SINERVO B. Local extinction risk of three species of lizard from Patagonia as a result of global warming. Canadian Journal of Zoology, 94.1, 49, 2015.

13. SINERVO B., MENDEZ-DE-LA-CRUZ F., MILES D.B., HEULIN B., BASTIAANS E., VILLAGRAN-SANTA CRUZ M., GADSDEN H. Erosion of lizard diversity by climate change and altered thermal niches. Science, 328.5980, 894, 2010.

14. TELEMECO R.S., GANGLOFF E.J., CORDERO G.A., POLICH R.L., BRONIKOWSKI A.M., JANZEN F.J. Physiology at near-critical temperatures, but not critical limits, varies between two lizard species that partition the thermal environment. Journal of Animal Ecology, 86.6, 1510, 2017.

15. ELITH J., PHILIPS S.J., HASTIE T., DUDIK M., CHEE Y.E., YATES C.J. A statistical explanation of MaxEnt for ecologists. Diversity and distributions, 17.1, 43, 2011.

16. MERT AHMET, KIRAÇ AKIN, Isparta-Sütçüler yöresinde Anatololacerta danfordi (Günter, 1876)'nin habitat uygunluk haritalamas1 [Habitat Suitability Mapping of Anatololacerta danfordi (Günter, 1876) in Isparta-Sütçüler District]. Bilge International Journal of Science and Technology Research, 1, 16, 2017.

17. SILLERO NEFTALÍ, CARRETERO MIGUEL A. Modelling the past and future distribution of contracting species. The Iberian lizard Podarcis carbonelli (Squamata: Lacertidae) as a case study. Zoologischer Anzeiger-A Journal of Comparative Zoology, 252.3, 289, 2013.

18. BARAN İ., ILGAZ Ç., AVCI A., KUMLUTAŞ Y., OLGUN K. Türkiye Amfibi ve Sürüngenleri [The Amphibians and Reptiles of Turkey], Ankara Tübitak Popüler Bilim Kitapları 207, 2013.

19. BELLATI A., CARRANZA S., GARCIA-PORTA J., FASOLA M., SINDACO R. Cryptic diversity within the Anatololacerta species complex (Squamata: Lacertidae) in the Anatolian Peninsula: evidence from a multi-locus approach. Molecular phylogenetics and evolution, 82, 219, 2015.

20. SILLERO N., GONÇALVES-SECO LUIS. Spatial structure analysis of a reptile community with airborne LiDAR data. International Journal of Geographical Information Science, 28.8, 1709, 2014. 
21. ARNOLD EDWIN NICHOLAS, ARRIBAS ÓSCAR, CARRANZA SALVADOR. Systematics of the Palaearctic and Oriental lizard tribe Lacertini (Squamata: Lacertidae: Lacertinae), with descriptions of eight new genera. Magnolia Press, 2007.

22. KUMAR SUNIL, et al. KUMAR S., SPAULDING S.A., STOHLGREN T.J., HERMANN K.A., SCHMIDT T.S., BAHLS L.L. Potential habitat distribution for the freshwater diatom Didymosphenia geminata in the continental US. Frontiers in Ecology and the Environment, 7.8, 415, 2009.

23. PHILLIPS STEVEN J., DUDIK MIROSLAV, SCHAPIRE ROBERT E. A maximum entropy approach to species distribution modeling. In: Proceedings of the twenty-first international conference on Machine learning. ACM, 83, 2004.

24. PHILLIPS STEVEN J., ANDERSON ROBERT P., SCHAPIRE ROBERT E. Maximum entropy modeling of species geographic distributions. Ecological modelling, 190.3, 231, 2006.

25. HUEY RAYMOND B. Temperature, physiology, and the ecology of reptiles. In: Biology of the Reptilia. 1982.

26. VICENZI NADIA, et al. VICENZI N., CORBALAN V., MILES D., SINERVO B., IBARGUENGOYTIA N. Range increment or range detriment? Predicting potential changes in distribution caused by climate change for the endemic high-Andean lizard Phymaturus palluma. Biological Conservation, 206, 151, 2017.

27. BUCKLEY LAUREN B., TEWKSBURY JOSHUA J., DEUTSCH CURTIS A. Can terrestrial ectotherms escape the heat of climate change by moving?. In: Proc. R. Soc. B. The Royal Society, 280: 1765. 20131149, 2013.
28. NAIMAN ROBERT J., DECAMPS HENRI, POLLOCK MICHAEL The role of riparian corridors in maintaining regional biodiversity. Ecological applications, 3.2, 209, 1993.

29. ACKLEY J.W., ANGILLETTA M.J., DENARDO D., SULLIVAN B., WU J. Urban heat island mitigation strategies and lizard thermal ecology: landscaping can quadruple potential activity time in an arid city. Urban ecosystems, 18.4, 1447, 2015.

30. SEARS MICHAEL W., RASKIN EVAN, ANGILLETTA JR, MICHAEL J. The world is not flat: defining relevant thermal landscapes in the context of climate change. Integrative and Comparative Biology, 51.5, 666, 2011.

31. HUEY RAYMOND B., LOSOS JONATHAN B., MORITZ CRAIG. Are lizards toast?. Science, 328.5980, 832, 2010.

32. INTERGOVERNMENTAL PANEL ON CLIMATE CHANGE. Climate Change 2014-Impacts, Adaptation and Vulnerability: Regional Aspects. Cambridge University Press, 2014.

33. SUNDBLAD E.-L., BIEL A., GÄRLING T. Intention to change activities that reduce carbon dioxide emissions related to worry about global climate change consequences. Revue Européenne de Psychologie Appliquée/European Review of Applied Psychology, 64.1, 13, 2014.

34. URRY J. Climate change and society. In: Why the social sciences matter. Palgrave Macmillan, London,. 45, 2015.

35. CLARK WOODROW W. Introduction. In: The Next Economics. Springer, New York, NY,. 1, 2013. 